\title{
The bacterial density of clinical rectal swabs is highly variable, correlates with sequencing contamination, and predicts patient risk of extraintestinal infection
}

\author{
Rishi Chanderraj 1,2, Christopher A. Brown ${ }^{2,3}$, Kevin Hinkle ${ }^{2}$, Nicole Falkowski ${ }^{2}$, Robert J. Woods ${ }^{1,4}$ and \\ Robert P. Dickson ${ }^{2,5,6,7^{*}}$ (1)
}

\begin{abstract}
Background: In ecology, population density is a key feature of community analysis. Yet in studies of the gut microbiome, bacterial density is rarely reported. Studies of hospitalized patients commonly use rectal swabs for microbiome analysis, yet variation in their bacterial density - and the clinical and methodologic significance of this variation-remains undetermined. We used an ultra-sensitive quantification approach—droplet digital PCR (ddPCR)—-to quantify bacterial density in rectal swabs from 118 hospitalized patients. We compared bacterial density with bacterial community composition (via 16S rRNA amplicon sequencing) and clinical data to determine if variation in bacterial density has methodological, clinical, and prognostic significance.

Results: Bacterial density in rectal swab specimens was highly variable, spanning five orders of magnitude $(1.2 \times$ $10^{4}-3.2 \times 10^{9} 16 \mathrm{~S}$ rRNA gene copies/sample). Low bacterial density was strongly correlated with the detection of sequencing contamination (Spearman $\rho=-0.95, p<10^{-16}$ ). Low-density rectal swab communities were dominated by peri-rectal skin bacteria and sequencing contaminants $(p<0.01)$, suggesting that some variation in bacterial density is explained by sampling variation. Yet bacterial density was also associated with important clinical exposures, conditions, and outcomes. Bacterial density was lower among patients who had received piperacillin-tazobactam ( $p=0.017)$ and increased among patients with multiple medical comorbidities (Charlson score, $p=0.0040$ ) and advanced age $(p=0.043)$. Bacterial density at the time of hospital admission was independently associated with subsequent extraintestinal infection ( $p=0.0028$ ), even when controlled for severity of illness and comorbidities.

Conclusions: The bacterial density of rectal swabs is highly variable, and this variability is of methodological, clinical, and prognostic significance. Microbiome studies using rectal swabs are vulnerable to sequencing contamination and should include appropriate negative sequencing controls. Among hospitalized patients, gut bacterial density is associated with clinical exposures (antibiotics, comorbidities) and independently predicts infection risk. Bacterial density is an important and under-studied feature of gut microbiome community analysis.
\end{abstract}

\footnotetext{
*Correspondence: rodickso@med.umich.edu

${ }^{7}$ Pulmonary and Critical Care Medicine, University of Michigan Health System, 6220 MSRB III / SPC 5642, 1150 W. Medical Center Dr, Ann Arbor, Ml 48109-5642, USA

Full list of author information is available at the end of the article
}

\section{Introduction}

The past decade has witnessed an explosion in gut microbiome research. Between 2013 and 2017, 12,900 gut microbiome publications were published; prior to that time it took four decades to reach 3000 studies on the topic [1]. This acceleration has been propelled by the 
advent and widespread use of $16 \mathrm{~S}$ rRNA gene ampliconbased sequencing $[2,3]$. The majority of these gut microbiome studies characterize microbial taxa as relative fractions of a sample sequence library (relative abundance). A key limitation of this approach is that it omits the study of the total population density (absolute abundance), a fundamental parameter in ecologic analysis [4]. The few studies that have considered the bacterial density of the gut microbiome have found that it is robust against confounding variables [5-7], and correlated with variation in disease status in a manner unappreciated by community composition alone $[5,6,8]$.

Rectal swabs are commonly used in gut microbiome studies due to their convenience and ubiquitous clinical use [9-11]. While the bacterial density of fecal specimens has been shown to have both methodologic and clinical/ prognostic significance $[5,6,8]$, the bacterial density of rectal swabs has not been reported. Methodologically, rectal swabs may be vulnerable to the sequencing contamination that plagues low-biomass microbiome studies [11-14]. Clinically, it is unknown if rectal swab bacterial density is influenced by clinical exposures (e.g., antibiotic use) or is prognostic of clinical outcomes.

To address these gaps, we quantified bacterial density in rectal swabs from 118 hospitalized patients using droplet digital PCR, an ultra-sensitive quantification technique. We compared bacterial density with community composition (using 16S rRNA gene amplicon sequencing), clinical exposures (e.g., antibiotics and comorbidities), and subsequent risk of culture-confirmed extraintestinal infection.

\section{Methods}

\section{Study setting and design}

We designed a retrospective cohort study using hospital admission rectal swabs previously collected, processed, and analyzed for a study of gut microbiome risk factors for Vancomycin-resistant Enterococcus (VRE) acquisition in 118 patients admitted to the University of Michigan Hospital in 2016-2017 [15]. The infection control practice throughout the study period was to perform routine surveillance for VRE using rectal swabs on eight adult hospital units, including intensive care units, the hematology and oncology ward, and the bone marrow transplant (BMT) ward, in concordance with recommendations from the Centers for Disease Control and Prevention (CDC) the Society for Healthcare Epidemiology of America [16]. All hospitalized patients had routine collection of rectal swabs on admission and weekly thereafter to screen for VRE. Rectal swabs specimens were collected with the $\mathrm{BD}^{\mathrm{TM}}$ ESwab Regular Collection Kit (Franklin, NJ). The prescribed practice at our institution during the study period was to acquire rectal swabs from patients in left lateral decubitus position. A rectal swab was inserted through the rectal sphincter 2-3 cm, rotated $360^{\circ}$, withdrawn, and checked for the presence of fecal soilage. These swabs were then were stored at -80 ${ }^{\circ} \mathrm{C}$.

The current study was a secondary analysis of a previously reported case-control study [15]. In the prior study, cases were defined as subjects with an initial VRE-negative swab followed by a VRE-positive swab when evaluated by selective culture. We matched each case subject to a control subject with an initial VRE-negative swab followed by repeat VRE-negative swab within the same time at risk. An additional matching factor was the unit from which the first positive VRE was recovered for cases or the matched swab after the time at risk for controls. For the current study, we restricted our analysis to admission rectal swabs (one swab per patient).

\section{Bacterial DNA isolation}

After confirming visible fecal soilage of rectal swab specimens, genomic DNA was extracted from rectal swabs, re-suspended in $360 \mu \mathrm{L}$ ATL buffer (cell lysis solution, Qiagen DNeasy Blood \& Tissue kit) and homogenized in fecal DNA bead tubes using a modified protocol previously demonstrated to isolate bacterial DNA [17]. This resulted in a homogenized $500 \mu \mathrm{L}$ specimen, half of which was used for ddPCR sequencing, and half of which was used for $16 \mathrm{~S}$ amplicon sequencing. ZymoBIOMICS Microbial Community DNA Standard (Zymo Research) was sequenced as a positive control. Sterile laboratory water and $\mathrm{AE}$ buffer (solution of $10 \mathrm{mM}$ Tris- $\mathrm{Cl} 0.5$ mM in EDTA; pH 9.0) used in DNA isolation were collected and analyzed as potential sources of contamination (negative controls). To minimize the potential for batch effects influencing our results, all specimens were extracted by a single laboratory technician using a single extraction kit.

\section{Bacterial density quantification}

Bacterial DNA was quantified using a QX200 Droplet Digital PCR System (BioRad, Hercules, CA). The technique partitions a single sample into 20,000 droplets. A standard PCR reaction then amplifies $16 \mathrm{~S}$ specific cDNA in each droplet, and each droplet is individually counted by the associated target dependent fluorescence signal as positive or negative. This allows for absolute $16 \mathrm{~S}$ copy number quantification without generating a standard curve [18-20]. Primers and cycling conditions were performed according to a previously published protocol [20]. To summarize, primers were $5^{\prime}$-GCAGGCCTAACACAT GCAAGTC-3' (63F) and 5'-CTGCTGCCTCCCGTA GGAGT-3' (355R). The cycling protocol was as follows: 1 cycle at $95^{\circ} \mathrm{C}$ for $5 \mathrm{~min}, 40$ cycles at $95^{\circ} \mathrm{C}$ for $15 \mathrm{~s}$, and 
$60{ }^{\circ} \mathrm{C}$ for $1 \mathrm{~min}, 1$ cycle at $4{ }^{\circ} \mathrm{C}$ for 5 min, 1 cycle at $90{ }^{\circ} \mathrm{C}$ for $5 \mathrm{~min}$, all at a ramp rate of $2{ }^{\circ} \mathrm{C} / \mathrm{s}$. The BioRad C1000 Touch Thermal Cycler was used for PCR cycling. Droplets were detected using the automated droplet reader (Bio-Rad, catalog no. 1864003), quantified using Quantasoft $^{\mathrm{TM}}$ Analysis Pro (version 1.0.596), and imported to $\mathrm{R}$ for visualization and statistical analysis. Both sterile water controls, as well as isolation controls, were run alongside rectal swab specimens.

\section{6s rRNA gene sequencing}

The V4 region of the 16s rRNA gene was amplified using published primers and the dual-indexing sequencing strategy described previously [17]. Sequencing was performed using the Illumina MiSeq platform (San Diego, CA), using a MiSeq Reagent Kit V2 (500 cycles), according to the manufacturer's instructions with modifications found in the standard operating procedure of the laboratory of Patrick Schloss [17, 21]. All samples were sequenced in a single sequencing run to minimize the potential for batch effects influencing our results.

\section{Clinical metadata}

We collected data from the electronic medical record to describe host health both by the severity of the acute illness that prompted hospitalization and by the severity of chronic disease before hospitalization. We measured acute illness and chronic disease with the Sequential Organ Failure Assessment Score (SOFA score) [22-25] and Charlson comorbidity index [26-28], respectively. We collected data on the antibiotic exposure of patients in the Emergency Department prior to collection of their initial rectal swab. A total 116 of 118 subjects were included in the clinical analysis, as two subjects had sensitive information inaccessible through the medical record.

We used infection-free survival to study the prognostic significance of bacterial density on rectal swabs. We defined extra-intestinal infection as the growth of a bacterial organism by traditional culture media in a site considered by clinicians to be "sterile" (blood, urine, ascites fluid, cerebrospinal fluid, sputum, deep tissue culture) meeting clinical criteria set by major medical societies and the Centers for Disease Control and Prevention [2935]. Clinical adjudication of positive culture growth led to categorization as colonization, contamination, or clinical infection.

We reviewed the electronic medical record documentation to determine the admitting diagnosis for patients in the cohort. We broadly classified admitting diagnoses into 7 categories: cardiopulmonary disorder (which included congestive heart failure, myocardial infarction, respiratory failure not attributable to pneumonia, and post-operative ICU stay after major cardiac surgery); primary neurologic disorder (which included intracranial hemorrhage, ischemic stroke, or post-operative recovery after major neurosurgery), sepsis syndrome (defined as a presumed infection on admission requiring the use of antibiotics), gastrointestinal disruption (which included inflammatory bowel disease, pancreatitis, bowel obstruction or perforation, or post-operative status after major gastrointestinal surgery), trauma, non-infectious complications of chemotherapy (which included acute renal injury, cytopenia without the presence of neutropenic fever, and nausea and vomiting attributable to chemotherapy), and non-infectious complications of bone-marrow transplantation (which included graft versus host disease as well as nausea and vomiting in the absence of recent chemotherapy administration).

\section{Statistical analysis of clinical metadata}

All analyses were performed using the $\mathrm{R}$ statistical programming language ( $\mathrm{v}$ 4.0.2) [36]. To account for the paired nature of the data, we built a linear mixed-effects model stratified by matched pair status and used clinical covariates to predict log transformed bacterial density. We constructed Kaplan-Meier curves and built a frailty model, also stratified by matched pair status, with the survival [37] (v 3.1-8) package in R. Pairwise significance was determined as appropriate by the Wilcoxon test with the Benjamini-Hochberg correction, Tukey's HSD test, and Mann-Whitney $U$ test. All tests used $p=0.05$ as a threshold for significance.

\section{$16 \mathrm{~S}$ gene amplicon analysis}

Sequence data were processed and analyzed using the software mothur v.1.43.0 [38] according to the standard operating procedure for MiSeq sequence data [17, 39]. We followed the mothur standard operating procedure without deviation, and no low-amplicon sequences were filtered during the analysis. To summarize, the SILVA rRNA database [40] (v. 132, silva.nr_v132.regionV4.align) was used as a reference for sequence alignment and taxonomic classification. K-mer searching with 8-mers was used to assign raw sequences to their closest matching template in the reference database, and pairwise alignment was performed with the Needleman-Wunsch [41] and NAST algorithms [42]. A k-mer-based naive Bayesian classifier [43] was used to assign sequences to their correct taxonomy with a bootstrap confidence score threshold of 80. Pairwise distances between aligned sequences were calculated by the method employed by Sogin et al. where pairwise distance equals mismatches, including indels, divided by sequence length [44]. A distance matrix was passed to the OptiCLUST clustering algorithm [45] to cluster sequences into "operational taxonomic units" 
(OTUs) by maximizing the Matthews correlation coefficient with a dissimilarity threshold of 3\% [46]. OTU numbers were arbitrarily assigned in the binning process and are referred to throughout the manuscript in association with their most specified level of taxonomy (typically genus or family). OTUs were classified using the mothur implementation of the Ribosomal Database Project (RDP) classifier and RDP taxonomy training set 16 (trainset16_022016.rdp.fasta, trainset16_022016.rdp.tax), available on the mothur website.

After clustering and classification of sequencing data, we evaluated differences in community structure with permutational multivariate analysis of variance (PERMANOVA) in the vegan package (v 2.0-4) [47] in R, and with the mvabund [48] package in $\mathrm{R}$. We determined the individual OTU differences driving separation of microbial communities with a random forest classification model built with the ranger package ( $\mathrm{v}$ 0.11.2) [49]. We used the caret ( $\mathrm{v}$ 6.0-84) [50] package in R for crossvalidation and hyperparameter optimization. We used latent class regression with the flexMix package in R [51] to determine the critical threshold at which rectal swabs are open to sequencing contamination. All OTUs were included in diversity and abundance analyses.

\section{Results}

\section{The bacterial density of rectal swabs is highly variable} and does not correlate with amplicon sequencing depth

We first sought to establish the variability of bacterial density in rectal swab specimens. Using ddPCR, we quantified bacterial density in 118 rectal swabs from hospitalized patients collected at the time of their admission. We compared this variation with extraction control specimens with sterile water used in DNA extraction $(n=3)$, and isolation control specimens $(n=6)$ (Table 1, Fig. 1$)$. The bacterial density in rectal swab specimens was highly variable, spanning five orders of magnitude (range 1.18 $\times 10^{4}-3.23 \times 10^{9} 16 \mathrm{~S}$ rRNA gene copies/specimen, IQR $4.63 * 10^{7} 16 \mathrm{~S}$ rRNA gene copies/swab) (Fig. 1A). All rectal swabs contained greater bacterial density than all negative control specimens: the minimum number of $16 \mathrm{~S}$ rRNA gene copies/specimen was almost double the maximum number of $16 \mathrm{~S}$ copies in negative control specimens. We thus concluded that the bacterial density in rectal swab specimens is highly variable, yet consistently greater than that of negative control specimens.

We also observed variation in the number of $16 \mathrm{~S}$ rRNA gene amplicon reads generated via Illumina MiSeq sequencing (Fig. 1B). We thus asked if the variation in specimen bacterial density (as quantified by ddPCR) correlates with the number of $16 \mathrm{~S}$ rRNA gene amplicon reads generated via Illumina MiSeq sequencing (as has been assumed in published studies [52, 53]). As shown
Table 1 Summary statistics for droplet digital PCR (ddPCR) and Illumina MiSeq results by specimen type

\begin{tabular}{llll}
\hline & Water & Isolation controls & Rectal swabs \\
\hline ddPCR 16S copies/sample & & \\
Mean & 14 & $3.14^{*} 10^{3}$ & $9.67^{*} 10^{7}$ \\
Median & 15 & $3.22^{*} 10^{3}$ & $3.17^{*} 10^{6}$ \\
Minimum & 9 & $1.41^{*} 10^{3}$ & $1.18^{*} 10^{4}$ \\
Maximum & 17 & $5.21^{*} 10^{3}$ & $3.23^{*} 10^{9}$ \\
Standard deviation & 2.4 & $1.22^{*} 10^{3}$ & $3.41^{*} 10^{8}$ \\
Interquartile range & 3.3 & $1.17^{*} 10^{3}$ & $4.63^{*} 10^{7}$ \\
Illumina MiSeq 16S reads/sample & & \\
Mean & $7.39^{*} 10^{5}$ & $5.37^{*} 10^{5}$ & $7.39^{*} 10^{5}$ \\
Median & $8.45^{*} 10^{5}$ & $5.57^{*} 10^{5}$ & $7.45^{*} 10^{5}$ \\
Minimum & $4.42^{*} 10^{5}$ & $2.39^{*} 10^{5}$ & 83 \\
Maximum & $9.29^{*} 10^{5}$ & $7.86^{*} 10^{5}$ & $1.46^{*} 10^{6}$ \\
Standard deviation & $2.60^{*} 10^{5}$ & $1.73^{*} 10^{5}$ & $2.23^{*} 10^{5}$ \\
Interquartile range & $2.44^{*} 10^{5}$ & $2.09^{*} 10^{5}$ & $2.95^{*} 10^{5}$ \\
\hline
\end{tabular}

in Fig. 1 and Table 1, we found far less variation in the number of MiSeq reads than we found in bacterial density. The average number of MiSeq $16 \mathrm{~S}$ reads was not significantly different between rectal swab specimens and water control specimens ( $p=0.99$; Tukey's range test) but was significantly different than isolation controls $(p$ $=0.04$; Tukey's range test). We next asked if variation in bacterial density correlates with variation in 16S rRNA gene amplicon reads. We found no correlation between the bacterial density of rectal swab specimens and the number of $16 \mathrm{~S}$ rRNA gene amplicon reads generated via MiSeq sequencing ( $p=0.59$, Fig. $1 C)$. We thus concluded that the number of amplicon reads could not reliably distinguish rectal swab specimens from negative control specimens, and the number of $16 \mathrm{~S}$ rRNA gene amplicon reads generated via MiSeq sequencing is unrelated to bacterial density, and should not serve as a proxy.

\section{Rectal swabs are vulnerable to sequencing contamination}

Low-biomass microbiome studies are vulnerable to contamination due to bacterial DNA present in reagents used in DNA extraction and library preparation $[12,13]$. Given the wide variation in bacterial density, we observed in rectal swab specimens, we asked if bacterial communities detected in rectal swab specimens contained any evidence of sequencing contamination. We characterized bacterial communities in rectal swabs and negative controls using $16 \mathrm{~S}$ rRNA gene amplicon sequencing. We detected unambiguous evidence of sequencing (background) contamination, as negative control communities were dominated by a single bacterial taxonomic group (OTU0001) classified as Pseudomonas (Fig. 2A). This same Pseudomonas (OTU0001) was detected in rectal 

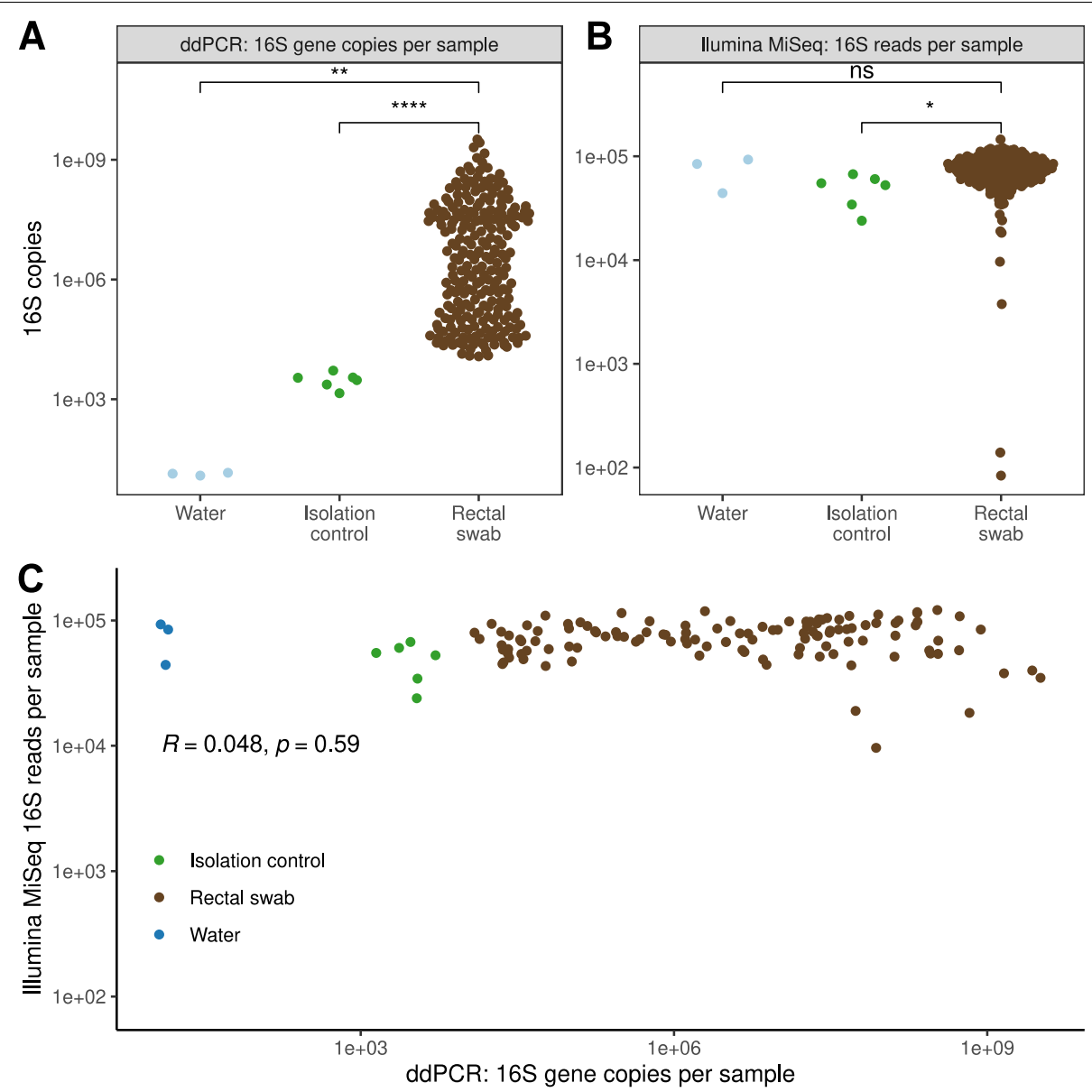

Fig. 1 The bacterial density of clinical rectal swabs is highly variable and is not correlated with sequencing depth via 16S rRNA gene amplicon sequencing. We used droplet digital PCR (ddPCR, BioRad) to quantify bacterial density by the absolute copy number of 165 gene in rectal swab specimens from 118 patients admitted to an acute care hospital. We used amplicon sequencing of the $16 \mathrm{~S}$ rRNA gene (MiSeq, Illumina) to characterize bacterial communities. A The bacterial density of rectal swabs was highly variable, spanning 5 orders of magnitude. Rectal swabs specimens had significantly higher bacterial density compared to negative controls ( $p<0.01$ for both comparisons with Tukey's multiple comparison of means). B The number of reads generated via $16 \mathrm{~S}$ rRNA amplicon sequencing did not distinguish rectal swabs from water control specimens ( $p=0.99$ for rectal swab specimens compared to water controls, $p=0.04$ for isolation controls, respectively, Tukey's comparison). C The number of amplicon reads per sample was not correlated with the bacterial density of rectal swab specimens (Pearson's $r=0.048, p=0.59$ ). Significance key: ns $p>0.05 ;{ }^{*} p \leq 0.05 ;{ }^{* *} p \leq 0.01 ;{ }^{* * *} p \leq 0.001 ;{ }^{* * * *} p \leq 0.0001$

swab specimens, and its relative abundance was strongly and negatively correlated with bacterial density (Fig. 2B). Visualizing the relationship between bacterial density and the relative abundance of the Pseudomonas contaminant revealed that there appeared to be a critical threshold above which bacterial density was not correlated with the abundance of the contaminant taxa. We used latent class regression to determine a critical threshold where bacterial density became strongly correlated with the relative abundance of the Pseudomonas contaminant, and we determined that above a threshold of $10^{6}$ copies/ specimen, the contaminant OTU was nearly undetected. Below $10^{6}$ copies/specimen, this Pseudomonas taxon was the dominant community member. Formal correlation testing revealed that the bacterial density of rectal swab specimens almost entirely explained the variation in the relative abundance of this contaminant bacterial DNA (Spearman $\rho=-0.95, p=2.2 * 10^{-16}$ ). Altogether, this sequencing contaminant was detected in $62 \%$ of all rectal swabs, and in $99 \%$ of swabs with a density lower than $10^{6}$ copies/swab. We thus concluded that rectal swab specimens are vulnerable to sequencing contamination, especially specimens with a density less than $10^{6} 16 \mathrm{~S}$ rRNA gene copies/specimen.

Our group has previously shown the ability to distinguish Pseudomonas aeruginosa, a common hospital acquired pathogen, from non-aeruginosa Pseudomonas spp. via $16 \mathrm{~S}$ rRNA gene amplicon sequencing [54]. We 

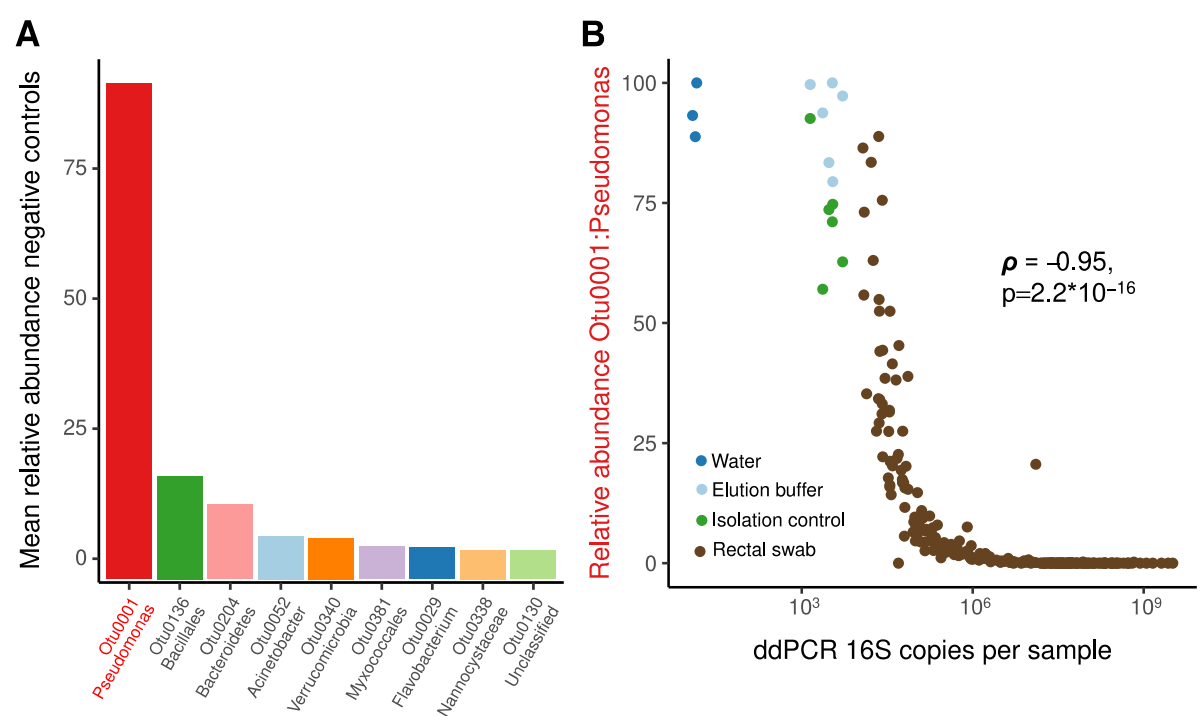

Fig. 2 The bacterial density of rectal swab specimens determines their vulnerability to sequencing contamination. A The bacterial DNA identified in negative sequencing controls $(n=9)$ was dominated by a single contaminant bacterial taxon (Otu0001: Pseudomonas). B This same Pseudomonas contaminant was present in rectal swab specimens, and variation in its relative abundance was almost entirely explained by the bacterial density of the specimen (Spearman $\rho=-0.95, p<2.2^{*} 10^{-16}$ )

therefore sought to determine if this contaminant OTU may represent Pseudomonas aeruginosa. To accomplish this, we analyzed our positive control samples from the ZymoBIOMICS Microbial Community DNA Standard, which contains a known $12 \%$ relative abundance of Pseudomonas aeruginosa. We noted the presence of 2 Pseudomonas classified OTUs in the mock community samples, OTU0001 present at an abundance of $0.2 \%$ and $0.1 \%$ in two of three of the mock community samples, and OTU0028 present at an abundance of $9-10 \%$ in all three mock community samples. Given the large difference in abundance of these two different Pseudomonas classified OTUs, one approximating the known relative abundance of Pseudomonas aeruginosa in the mock community, and one with extremely low abundance, we inferred that OTU0001 was a non-aeruginosa Pseudomonas.

We next investigated whether variation in bacterial density is correlated with variation in community composition. To accomplish this, we interrogated the bacterial community structure of rectal swab specimens and asked how community composition varies with bacterial density. First, we visualized communities using principal component analysis, color-coding specimens by bacterial density (less than or greater than $10^{6} 16 \mathrm{~S}$ rRNA gene copies/specimen (Fig. 3A). This demonstrated clear separation of specimens by bacterial density, confirmed statistically by PERMANOVA $(p<0.001)$ and by resampling of a generalized linear model (mvabund, $p<0.001$ ). We next interrogated which specific bacteria drove the overall difference in community composition across specimens varying in bacterial density. To accomplish this, we built a Random Forest classification model and applied a permutation heuristic developed to correct for feature importance bias [55] and identified those features that were significant at $p<0.05$ (Fig. 3B). The model identified nine bacterial taxa correlated with bacterial density (Fig. 3C). The previously identified Pseudomonas contaminant (OTU0001) was the most strongly correlated taxonomic group, followed by two common sequencing contaminants, Flavobacterium (OTU0029) and another Pseudomonas (OTU0008). These were followed by two commonly reported skin bacteria, Staphylococcus (OTU0016) and Corynebacterium (OTU0042). Four gut bacterial taxa were correlated with bacterial density, Bacillus (OTU000058), Lactobacillus (OTU0026), Bacteroides (OTU0006), and Akkermansia (OTU0005). When we restricted our analysis to swabs above the contamination threshold of $10^{6} 16 \mathrm{~S}$ copies/sample (above), we identified three significant taxa: the previously identified Lactobacillus (OTU0026), as well as Anaerococcus (OTU0037) and Synergistaceae (OTU 0104). Lactobacillus (OTU0026), a known bacteriocin-producing probiotic bacteria [56, 57], was the most strongly correlated taxonomic group in the subset analysis, and was inversely correlated with bacterial density $\left(p=9.9^{*} 10^{-3}\right)$. This suggests that the relationship between bacterial density and community composition was not entirely attributable to specimen quality or sequencing contamination, but also reflects authentic correlations across gut communities. We thus concluded that bacterial density and bacterial 


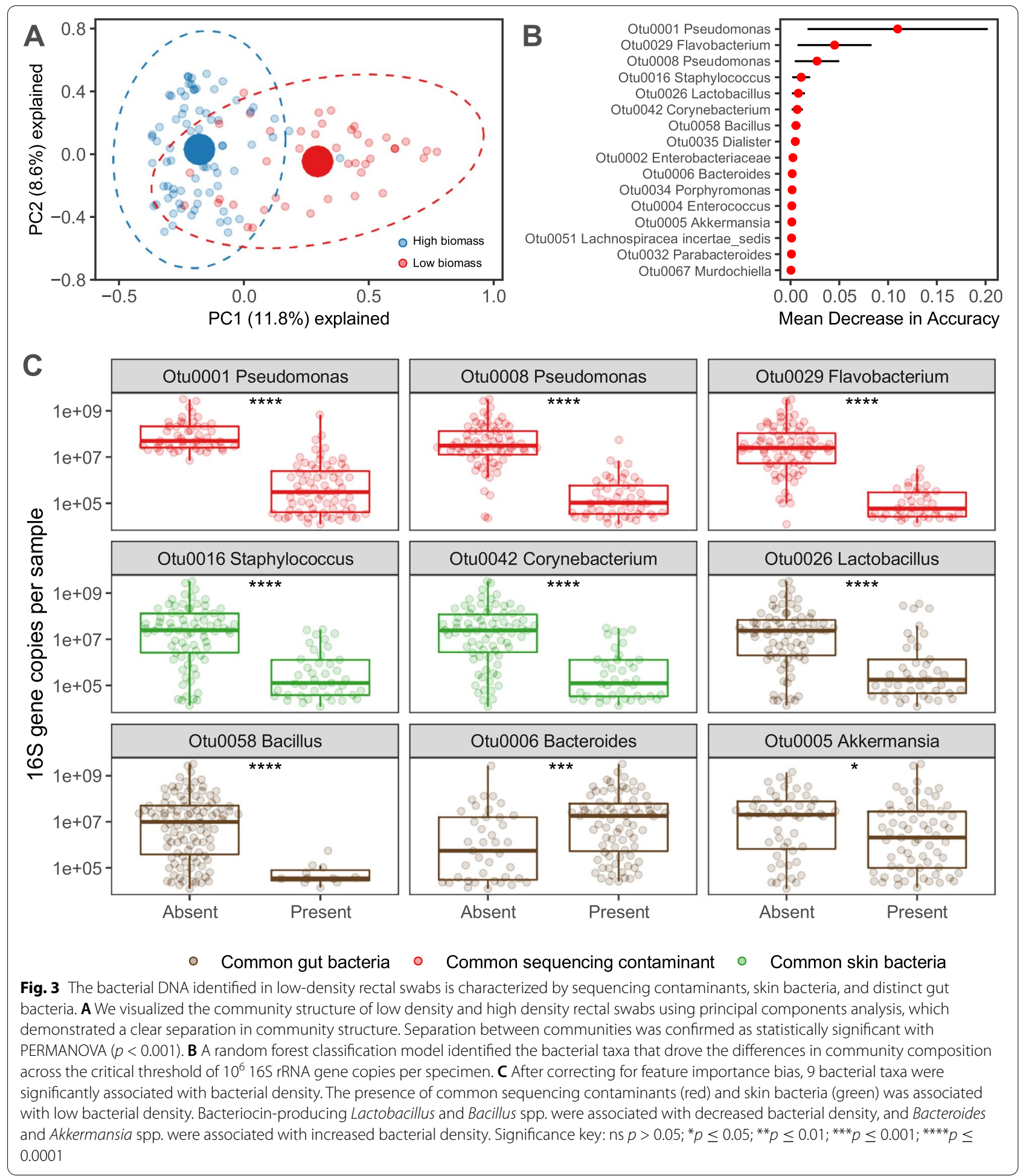

community composition are correlated, reflecting variation both in sampling/sequencing contamination as well as intrinsic differences within lower gut bacterial communities.
The bacterial density of rectal swab specimens is correlated with clinical comorbidities and clinical exposures

Having established that bacterial density variation in rectal swab specimens is not entirely attributable to 
variation in sampling and sequencing contamination, we next interrogated the clinical significance of bacterial density variation. To accomplish this, we compared

Table 2 Demographics and comorbidities of cohort

\begin{tabular}{ll}
\hline & $\boldsymbol{N}=\mathbf{1 1 6}$ (out \\
of 118 swabs) \\
\hline Demographics & $\boldsymbol{N}$ (proportion) \\
Age (mean \pm SE) & $60.0 \pm 1.37$ \\
Female & $52(0.45)$ \\
Non-white race & $17(0.15)$ \\
Comorbidities & \\
C. difficile infection & $15(0.13)$ \\
Leukemia & $30(0.26)$ \\
Lymphoma & $14(0.12)$ \\
Bone marrow transplant & $20(0.17)$ \\
Solid organ malignancy & $81(0.70)$ \\
Metastatic malignancy & $54(0.47)$ \\
Diabetes & $47(0.41)$ \\
Coronary artery disease & $18(0.16)$ \\
Congestive heart failure & $38(0.33)$ \\
COPD & $53(0.46)$ \\
Peripheral vascular disease & $7(0.06)$ \\
End stage renal disease & $46(0.40)$ \\
Connective tissue disease & $5(0.040)$ \\
Peptic ulcer disease & $16(0.14)$ \\
Cirrhosis & $12(0.10)$ \\
Cerebrovascular disease & $24(0.21)$ \\
Hemiplegia & $10(0.10)$ \\
Dementia & $4(0.03)$ \\
Charlson Score (mean \pm SE) & $4.0 \pm 0.19$ \\
Cardiopulmonary disorder & \\
Gastrointestinal disorder & $22(0.19)$ \\
Complications of chemotherapy & $12(0.1)$ \\
Neurologic abnormality & $36(0.31)$ \\
Sepsis syndrome & $3(0.02)$ \\
& $34(0.29)$ \\
& $4(0.03)$ \\
& $5(0.04)$ \\
\hline
\end{tabular}

bacterial density variation with patient clinical characteristics, including demographics, comorbidities, antibiotic exposure, and VRE colonization. Gender, race, specific comorbidities, and reason for admission were not individually associated with bacterial density variation (Table 2, see Supplemental Table 1 for univariate comparisons). Out of 118 patients in the cohort, $116 \mathrm{had}$ data accessible through the electronic medical record and were included in the analysis.

Recent studies have demonstrated that antibiotics differ in their impact on gut microbiota $[58,59]$, with piperacillin-tazobactam causing more disruption that other antibiotics $[58,59]$. Therefore, we asked if antibiotics differ in their impact on the bacterial density of admission rectal swabs. We first characterized the antibiotic exposure in our cohort (Table 3, Supplemental Table 2). There were a total of 104 antibiotic doses administered to the cohort prior to rectal swab collection. Vancomycin $(n=$ $35)$, metronidazole $(n=22)$, piperacillin-tazobactam ( $n$ $=20)$, and cefepime $(n=18)$ were the most administered antibiotics. We compared the mean bacterial density in admission rectal swabs between patients who were and were not exposed to each antibiotic with the MannWhitney $U$ test. We found that only piperacillin-tazobactam was associated with lower bacterial density ( $p=$ $0.006)$, consistent with prior work $[58,59]$.

Next, we asked if bacterial density was correlated with clinical covariates. To account for the prior matched case-control study design, we built a mixed effects model incorporating the matched pair as a random intercept. We used age, antibiotic exposure, admission diagnosis, chronic comorbidities (via the Charlson comorbidity index [26-28]), and acute severity of illness (via the Sequential Organ Failure Assessment, or SOFA, score [22-25]) to predict the log-transformed bacterial density of rectal swabs. Given our finding that only piperacillintazobactam was significantly associated with bacterial burden, it was the only antibiotic included in the model. Increased age and comorbidity burden were all independently associated with increased bacterial density (Table 4, Fig. 4). Every decade of age was associated with a $0.43 \pm 0.40$ log-fold increase in 16S rRNA gene copies/

Table 3 Antibiotic exposure for cohort

\begin{tabular}{|c|c|c|c|c|}
\hline \multicolumn{5}{|c|}{ 16S rRNA gene copies/sample \pm SE (log scale) } \\
\hline & $\begin{array}{l}\text { Subjects treated } N \\
\text { (proportion) }\end{array}$ & No treatment & Received antibiotic & $P$ value \\
\hline Vancomycin & $35(0.3)$ & $15.18 \pm 0.39$ & $14.81 \pm 0.53$ & 0.58 \\
\hline Metronidazole & $22(0.19)$ & $15.03 \pm 0.37$ & $15.21 \pm 0.55$ & 0.79 \\
\hline Piperacillin-tazobactam & $20(0.17)$ & $15.46 \pm 0.34$ & $13.15 \pm 0.70$ & ${ }^{* *} 0.006$ \\
\hline Cefepime & $18(0.16)$ & $14.95 \pm 0.35$ & $15.70 \pm 0.72$ & 0.35 \\
\hline
\end{tabular}


Table 4 Fixed effects in linear mixed effects model stratified by matched pair of features associated with bacterial density (log $16 \mathrm{~S}$ copies/specimen)

\begin{tabular}{lll}
\hline & Coefficient $\mathbf{( 9 5 \% ~ C l )}$ & $\boldsymbol{P}$ value \\
\hline Piperacillin-tazobactam & $-1.84(-3.26$ to -0.42$)$ & $0.017^{*}$ \\
Age (decade) & $0.43(0.04-0.83)$ & $0.043^{*}$ \\
Charlson comorbidity index & $0.45(0.16-0.74)$ & $0.004^{*}$ \\
SOFA Score & $0.07(-0.13-0.27)$ & 0.51 \\
VRE colonization & $-0.073(-1.18-1.06)$ & 0.90 \\
Admission diagnosis & & \\
$\quad$ Cardiopulmonary disorder & $0.67(-5.421-6.707)$ & 0.84 \\
$\quad$ Neurologic abnormality & $2.41(-4.534-9.273)$ & 0.52 \\
$\quad$ Trauma & $1.35(-5.104-7.798)$ & 0.70 \\
$\quad$ Sepsis syndrome & $1.45(-4.582-7.428)$ & 0.65 \\
$\quad$ Non-infectious transplant com- & $-0.53(-7.275-6.276)$ & 0.89 \\
plication & & \\
$\quad$ Gastrointestinal abnormality & $2.30(-3.944-8.433)$ & 0.49 \\
$\quad$ Complications of chemotherapy & $0.40(-5.607-6.357)$ & 0.90 \\
REML criteria at convergence: 571.6 & & \\
\hline
\end{tabular}

specimen $(p=0.043)$, and every point increase in the Charlson comorbidity index (signifying more comorbidities) was associated with an average of $0.45 \pm 0.29$ log-fold increase in 16S rRNA gene copies/specimen $(p$ $=0.0040)$. Piperacillin-tazobactam exposure was associated with a $1.84 \pm 1.42 \log$-fold decrease in $16 \mathrm{~S}$ rRNA gene copies/specimen $(p=0.017)$. We noted that neither VRE colonization status nor admission diagnosis were associated with bacterial burden after controlling for age, antibiotic exposure, and chronic comorbidities. We concluded that patient demographics, comorbidities, and antibiotic exposure were all associated with variation in rectal swab bacterial density, confirming the clinical and biological significance of this feature of gut microbial communities.

Having discovered an association between bacterial density and clinical comorbidities and exposures, we next sought to determine if these associations could be due to bias introduced during rectal swab sampling. While we performed an informal quality control check by verifying fecal soilage of the sequenced rectal swabs, in this retrospective study, we were unable to verify that specimen acquisition was performed in a uniform manner for every subject. We thus asked if variation in nursing practices across different patient units was associated with bacterial density. To accomplish this, we compared the bacterial density across unit of admission. We found no collective difference in bacterial density across units (Kruskal-Wallis test, $p=0.33$, Supplemental Table 3, Supplemental Fig. 1), nor any significant differences between individual units of admission when comparing mean bacterial density with Tukey's HSD test (Supplemental Table 4). Given the technical difficulty of sampling a mechanically ventilated patient, we next asked if the bacterial density of rectal swabs acquired from mechanically ventilated patients was systematically lower than non-mechanically ventilated patients. We found that the bacterial density of rectal swabs was increased among patients receiving mechanical ventilation (Difference in means $1.22 \log 16 \mathrm{~S}$ copies/sample, 95\% CI 0.15-2.43 log

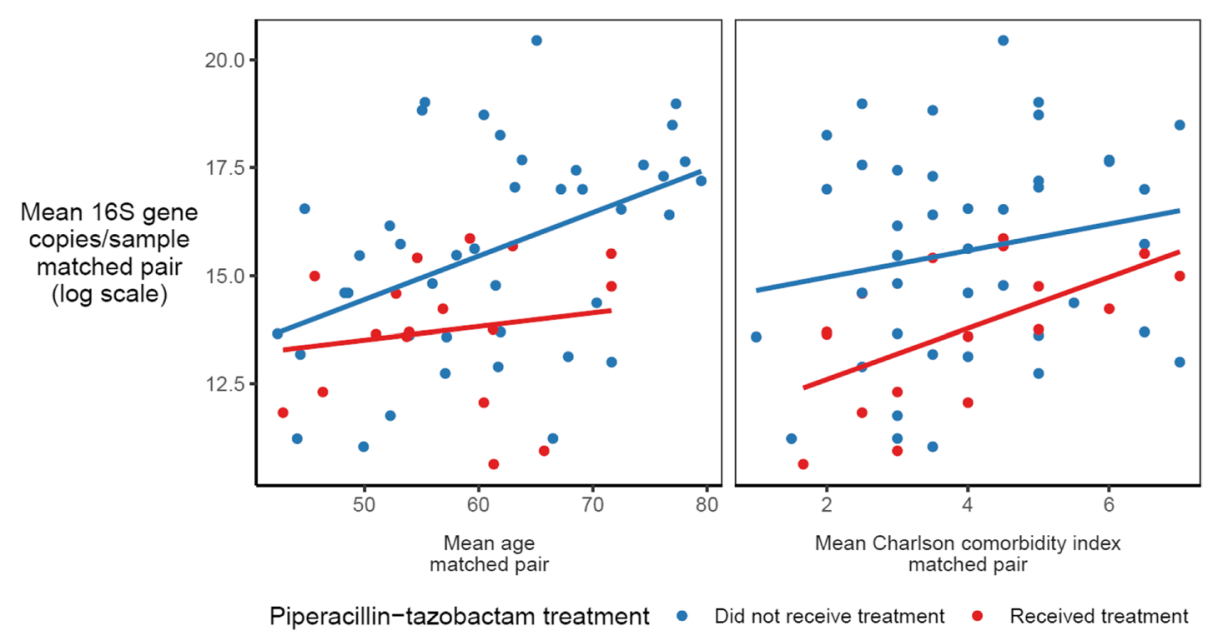

Fig. 4 The bacterial density of rectal swabs is strongly associated with piperacillin-tazobactam use. Bacterial density of rectal swabs was compared with clinical features and exposures using multivariable linear mixed-effect regression, stratified by matched case/control pair. Piperacillin-tazobactam exposure was associated with a $1.8 \mathrm{log}$ fold decrease in bacterial density $(\beta=-1.83, p=0.017)$. Bacterial density was positively correlated with patient age and medical comorbidities (as described by the Charlson comorbidity score) (increase in decade of age $\beta=$ $0.43, p=0.03$; Charlson comorbidity score $\beta=0.45, p=0.0040$ ) 
16S copies/sample, $p=0.043$ by $t$ test). We added both the unit of admission and mechanical ventilation status to our original model of bacterial density and found that our previous findings still held, and neither of these two possible confounding variables were significantly associated with bacterial density (Supplemental Table 5).

\section{The bacterial density of rectal swab specimens} is associated with subsequent extra-intestinal infections

Several studies have shown that in hospitalized patients, the gut microbiome serves as a reservoir for potentially infectious pathogens [5, 60-64]. Therefore, we asked if bacterial density variation is associated with subsequent extra-intestinal infections in hospitalized patients (including culture-confirmed bacteremia, pneumonia, urinary tract infections, spontaneous bacterial peritonitis, and soft tissue infections; Supplemental Tables 6 and 7). We first constructed Kaplan-Meier curves of infection-free survival in the cohort. Using a threshold of $10^{6}$ 16S rRNA gene copies/specimen, we found that patients with low bacterial density were more likely to be alive and infection-free at both 7 and 14 days after sampling $(p$
$=0.016$ by the log-rank test, Fig. 5). We then constructed a single variable frailty model stratified by matched pairs to predict infection-free survival in the study cohort as a function of the bacterial density at the time of admission. We found that every log-fold increase in bacterial density associated with an increased hazard rate of infection by $17 \%(p=0.0079)$.

Given our findings that age, comorbidities, and antibiotics are associated with bacterial density, we next asked if bacterial density is independently associated with subsequent infection, or is merely an indirect measure of susceptibility. We built a multivariable frailty model to stratified by matched pairs to account for the paired nature of the data. We incorporated age, piperacillintazobactam exposure, VRE colonization, chronic comorbidities (via the Charlson comorbidity index), and acute severity of illness (via the SOFA score) into the model. We included an admission diagnosis of sepsis syndrome in the model to determine if differences in infectionfree survival were driven by new infections or by infections present on admission. In this multivariable model, only bacterial density was associated with subsequent

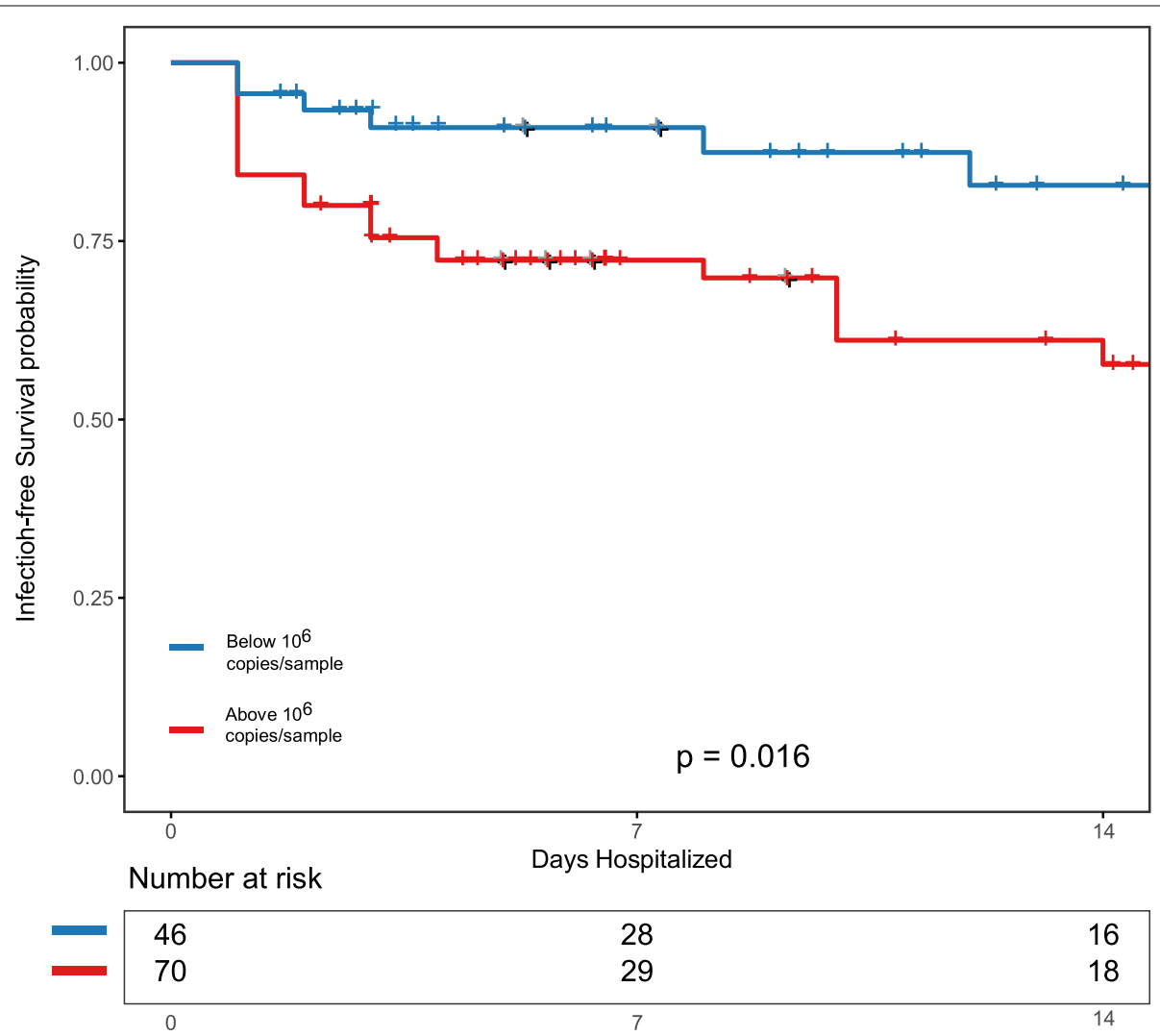

Fig. 5 The bacterial density of rectal swabs at the time of hospital admission is predictive of subsequent extra-intestinal infections. Kaplan-Meier curves of infection-free survival in our cohort of hospitalized patients. Cross tick-marks represent censored patients. Using a threshold of $10^{6} 16 \mathrm{~S}$ rRNA gene copies/specimen, we found that patients with high bacterial density were more likely to have extraintestinal infections at 7 and 14 days following sampling ( $p=0.016$ with stratified log-rank) 
infection (HR 1.21 $\pm 0.16, p=0.0028$, Table 5, Fig. 6). To determine if these associations still held after including possible confounding variables, we constructive an alternative model which included both mechanical ventilation status and unit of admission as covariates. We found that these possible confounding variables were not significantly associated with subsequent infection, and bacterial density remained the only predictor of subsequent infection (Supplemental Table 8).

\section{The bacterial community composition of rectal swabs} is associated with subsequent extra-intestinal infection

Having established that bacterial density of rectal swabs is predictive of subsequent infections, we next asked if

Table 5 Multivariable frailty model of features associated with bacterial infection

\begin{tabular}{llc}
\hline & Hazard ratio $\mathbf{9 5 \%}$ Cl) & P value \\
\hline log (copies 16S/sample) & $1.21(1.067-1.378)$ & $0.003^{* *}$ \\
SOFA Score & $0.99(0.866-1.125)$ & 0.845 \\
Charlson Comorbidity Index & $1.02(0.947-1.092)$ & 0.650 \\
VRE colonization & $0.63(0.308-1.298)$ & 0.211 \\
Piperacillin-tazobactam & $2.32(0.899-5.986)$ & 0.082 \\
Admission diagnosis of sepsis & $2.20(0.981-4.944)$ & 0.056 \\
Number of events $=37$ & Likelihood ratio test: $p<2^{*} 10^{-8}$ & Concordance: 0.857 \\
\hline
\end{tabular}

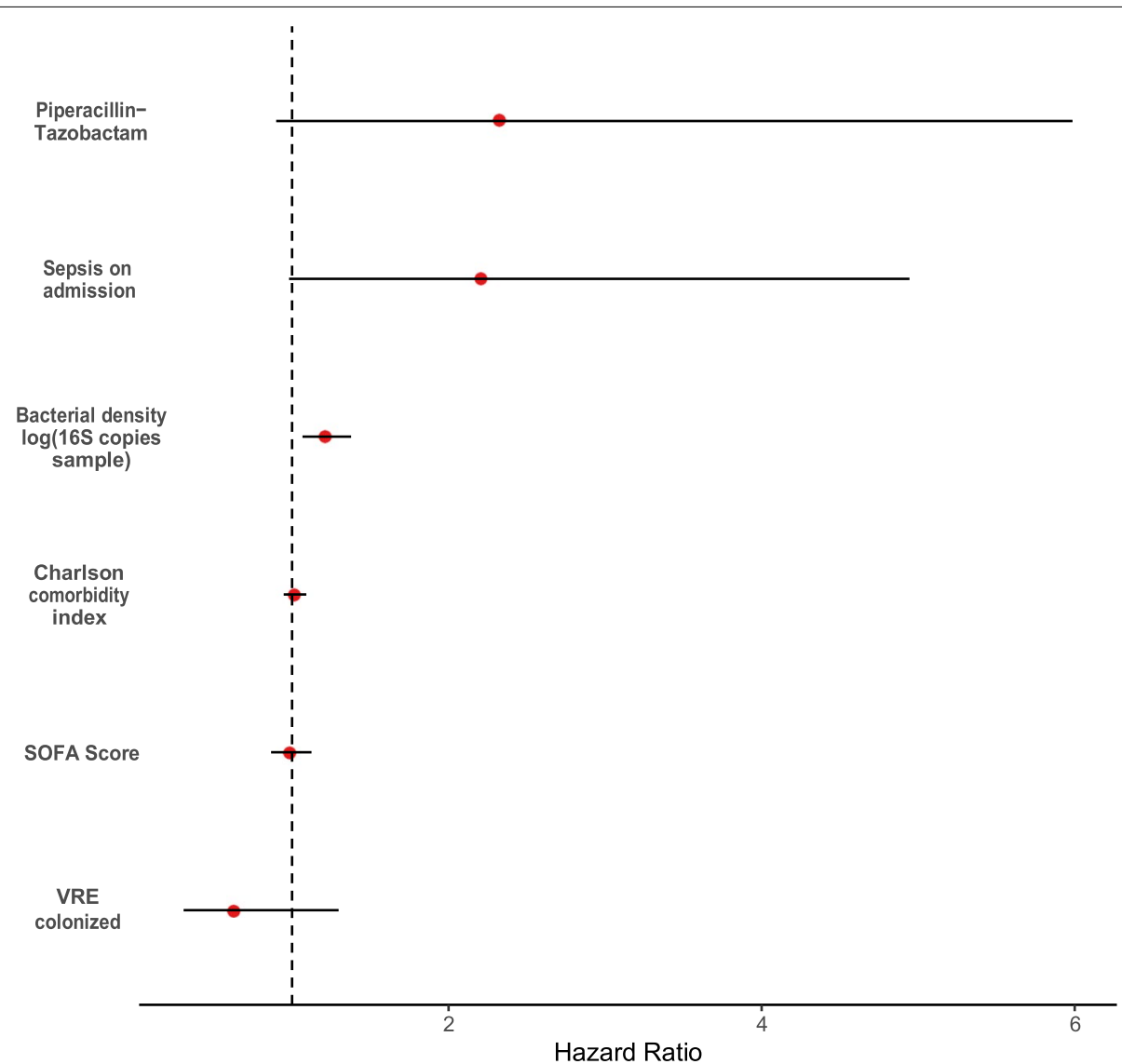

Fig. 6 The bacterial density of rectal swabs predicts risk of extraintestinal infection in multivariate analysis. Forest plot for hazard ratio from frailty analysis of infection-free survival, stratified by matched pair. The bacterial density of clinical rectal swabs predicts total infection-free days $(p=$ 0.0028 ) with a hazard ratio of 1.21 for every log fold increase in 165 gene copies/sample. This remained significant after controlling for severity of acute illness, chronic comorbidities, antibiotic use, and admission for sepsis syndrome 

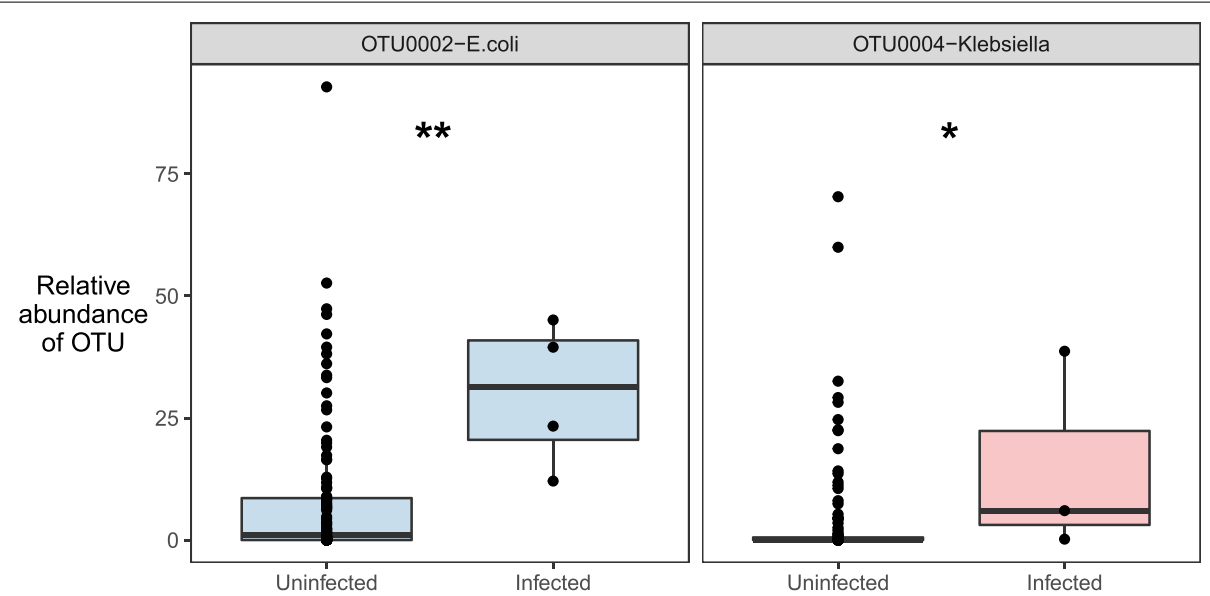

Fig. 7 Admission gut microbiota predict enteric gram-negative infection. We found patients with extra-intestinal $E$. coli infection had a greater abundance of OTU0002 ( $p=0.0060$ by Wilcoxon-Rank sum test), and patients with extra-intestinal Klebsiella infection had a greater abundance of OTU003 on admission rectal swab ( $p=0.020$ by Wilcoxon-Rank sum test). Significance key: ns $p>0.05 ;{ }^{*} p \leq 0.05 ;{ }^{* *} p \leq 0.01 ;{ }^{* * *} p \leq 0.001 ;{ }^{* * * *} p \leq$ 0.0001

the observed association was solely an artifact of sampling technique or was reflective of biologically meaningful differences in microbiota structure. To accomplish this, we determined if bacterial community composition could predict extra-intestinal infection. We built a constrained PERMANOVA model stratified by matched case control pairs. We detected a statistically significant separation in the gut communities between patients who did and did not develop extra-intestinal infection $(p=0.034)$. Next, we asked which taxa drove the difference in community structure. We built a random forest classification model incorporating clinical co-variates (the SOFA score and the Charlson comorbidity index), reason for admission, community composition, VRE colonization, and matched pair number to determine which bacterial taxa were predictive of infection. The model identified several taxa predictive of infection after correcting for feature importance bias (Supplemental Table 9). We noted that the same Lactobacillus taxa correlated with decreased bacterial density (OTU 0026) was identified as a feature protective against infection (OR 0.47, 95\% CI 0.32-0.71, $p=0.0002$ ). We noted that the only taxa correlated with both bacterial density and extra-intestinal infection was the previously identified Lactobacillus (OTU0026), and no sequencing contaminants were identified as associated with infection (after excluding OTU0001). We thus concluded that both community composition and bacterial density of admission rectal swabs is associated with increased risk extra-intestinal infection.

Prior studies have shown that pathogen colonization at the time of ICU admission is predictive of subsequent infection [64]. We therefore asked if we could detect matches between gut microbiota and distant site clinical isolates. We focused on the most abundant Enterobacteriaceae taxa (OTU0002, and OTU0003) and found that patients with extra-intestinal Escherichia coli infections had a greater abundance of OTU0002 ( $p=0.0060$ by the Wilcoxon-Rank sum test, Fig. 7), and patients with extraintestinal Klebsiella infection had a greater abundance of OTU003 on admission rectal swab ( $p=0.020$ by the Wilcoxon-Rank sum test). We found that both OTUs were exclusively identical to Enterobacteriaceae-classified taxa when comparing closely aligned sequences from the SILVA rRNA database, including Escherichia coli, Enterobacter spp., and Klebsiella pneumoniae. Given the concordance between rectal swab microbiota and distal clinical isolates, we concluded that pathogen colonization detected on rectal swab specimens was predictive of enteric gram-negative infection, consistent with prior studies [64].

\section{Discussion}

Our findings demonstrate that rectal swab bacterial density is highly variable, and that this variability is of methodological, clinical, and prognostic significance. We found that $16 \mathrm{~S}$ gene amplicon sequencing of rectal swab specimens was vulnerable to sequencing contamination and that the influence of contamination was almost entirely dependent on the bacterial density of the specimen. We found evidence that bacterial density was not merely a marker of sampling adequacy, as it was both associated with clinical comorbidities and exposures and predictive of infection-free survival. Our findings suggest that the bacterial density of rectal swab samples is an essential but overlooked ecologic feature in the study of the gut microbiome in hospitalized patients. 
Our key findings are aligned with those of prior studies. In culture-based studies, bacterial density predicted the onset of sepsis and pneumonia among critically ill patients $[65,66]$, a finding congruent with our cultureindependent results. Similar to other studies using culture-independent bacterial quantification, we found that bacterial density had clinical associations unappreciated by standard $16 \mathrm{~S}$ gene amplicon sequencing $[5,6,8]$. In contrast to prior work, our ultra-sensitive quantification technique (ddPCR) was able to quantify variation in low and high biomass specimens with similar precision $[20$, $67,68]$ and allowed us to quantify the total number of copies of the $16 \mathrm{~S}$ gene present in a rectal swab specimen without reference to the absolute abundance of individual species. Taken together with prior studies, our findings suggest that the measurement and analysis of bacterial density can provide methodological, clinical, and prognostic insights into gut microbiome studies.

The bacterial density of rectal swabs has methodological importance, as it precisely quantifies the risk of sequencing contamination, an underappreciated challenge in gut microbiome studies. Many of our rectal swab specimens had very low bacterial density, comparable to what is commonly seen in low biomass microbiome studies, such as those of the lung $[69,70]$. Given this wide variation, many rectal swabs were vulnerable to sequencing contamination [12-14], a finding compatible with prior studies [11]. To our knowledge, our study is the first to describe the strong association between bacterial density and sequencing contamination, as the level of sequencing contamination in these specimens was negatively correlated with bacterial density. The quantification of bacterial density is thus clarifying in microbiome studies and should be strongly considered as a complementary assay to discriminate legitimate signals from those of background contamination.

We found that bacterial density holds clinical significance, as it was associated with both clinical comorbidities and antibiotic exposure in a manner consistent with prior literature. Previous studies have shown that gut bacterial density increases with increased gut transit time [7]. We found that age and medical comorbidities, two features leading to decreased gut motility and increased transit time [71-73], were positively correlated with bacterial density. Among all administered antibiotics, we found that only piperacillin-tazobactam had a significant effect on the bacterial density of rectal swab specimens. This is concordant with a recent study using $16 \mathrm{~S}$ amplicon sequencing, which showed that piperacillin-tazobactam caused more disruption to gut microbiota than other antibiotics [58].

Our study found that bacterial density holds prognostic significance, as it predicts the risk of infection during hospitalization. When controlling for acuity of illness, chronic medical comorbidities, and age, bacterial density remained significant, while these previously validated predictors lost importance. We recently demonstrated that the gut microbiota of hospitalized patients undergoes rapid and profound change [15] and that the majority of bacterial species present on admission are not present later in hospitalization. Given this rapid change, a global metric of bacterial density that captures information about the population rather than individual members of the population may be a more useful index of the dynamic state of the gut microbiome in hospitalized patients. Further study with longitudinal sampling of gut microbiota is needed to investigate this phenomenon.

We acknowledge that some of the observed variation in bacterial density was caused by variation in the specimen acquisition technique, as we were unable to determine whether the clinical nursing staff perfectly adhered to prescribed specimen acquisition protocols. In addition, we found that skin flora and common contaminants were present in low-density specimens. We do note that the hospital protocol at the University of Michigan dictates that nursing staff perform and informal quality control check by verifying the presence of fecal soilage after rectal swab collection, which we verified immediately prior to specimen processing. We also evaluated for systematic differences between nursing staff in different hospital units, and for significant differences between technically challenging rectal swabs acquired from mechanically ventilated patients and found no evidence of systematic bias in these indirect analyses. Despite this limitation, these rectal swab specimens predicted the onset of infection with both bacterial density and community composition. The differences in community composition between infected and uninfected patients were not driven by sequencing contaminants or skin flora but rather by enteric organisms, including gram-negative organisms that matched distal clinical isolates and known probiotic Lactobacillus bacteria [56, 57]. Given that the same set of rectal swabs predicted the onset of infection when characterized by both bacterial density and community composition, we believe that it is unlikely that the observed variation is due solely to the specimen acquisition technique.

Some studies have questioned the use of rectal swab specimens for the characterization of gut microbiota by demonstrating that temporally discordant fecal and rectal swab specimens have discordant gut microbiota [67]. Those results are inconsistent with other studies, which show concordance between rectal swab and fecal specimens in hematology-oncology patients [11], critically ill patients [74], and healthy outpatients [9, 10]. Our group and others have shown that gut microbiota undergo 
rapid and temporally dependent changes in hospitalized patients $[15,75,76]$; therefore, the finding that temporally discordant samples show large differences in observed microbiota is unsurprising. This study adds to the growing body of literature demonstrating the clinical utility of rectal swab specimens for the characterization of gut microbiota, and we replicate findings that admission rectal swabs are predictive of infection and outcomes in ICU patients [64, 77].

This retrospective cohort study using a convenience sample of rectal swabs has limitations that should prompt further validation and study. As a single-center study, our results may not be generalizable beyond the observed cohort. We quantified bacterial density using DNA quantification of individual timepoints, which cannot reliably distinguish living bacteria from dead bacteria or describe the dynamic variation in bacterial density throughout hospitalization. We also could not reliably record the mass of fecal material present on our rectal swab specimens or normalize the bacterial density of rectal swabs to the mass of fecal material on those swabs. Despite these limitations, which should obscure any clinically meaningful associations, we were able to detect significant associations between bacterial density, clinical covariates, and infection-free survival.

\section{Conclusions}

Population density is a fundamental parameter in understanding the health and function of any ecosystem, but has largely been ignored in the study of the gut microbiome. Here, we demonstrate the methodological, biological, and clinical importance of bacterial density quantification. Our findings should prompt further study of this fundamental parameter of the gut microbial ecosystem.

\begin{abstract}
Abbreviations
EDTA: Ethylenediaminetetraacetic acid; pH: Potential of hydrogen; DNA: Deoxyribonucleic acid; cDNA: Complementary DNA; rRNA: Ribosomal ribonucleic acid; OTU: Operational taxonomic unit; PCR: Polymerase chain reaction; rpm: Revolutions per minute; ddPCR: Droplet digital PCR; V4: Fourth hypervariable region of the $16 S$ gene; IQR: Interquartile range; SOFA: Sequential organ failure score; PERMANOVA: Permutational analysis of variance; PIMP: Permutation importance; VRE: Vancomycin-resistant enterococcus.
\end{abstract}

\section{Supplementary Information}

The online version contains supplementary material available at https://doi. org/10.1186/s40168-021-01190-y.

Additional file 1: Supplemental Table 1. Univariate comparisons of difference in bacterial density by demographics and comorbidities. Supplemental Table 2. Total antibiotic exposure in the cohort. Supplemental Table 3. Summary statistics of bacterial density by hospital unit. Supplemental Table 4. Tukey HSD comparisons of bacterial density by unit of admission. Supplemental Table 5. Alternative linear mixed effects model of features associated with bacterial density (log 165 copies/specimen) including unit of admission and mechanically ventilated status. Supplemental Table 6. Composite outcomes in the cohort. Supplemental Table 7. Pathogens isolated in cohort. Supplemental Table 8. Alternative multivariable frailty model of features associated with bacterial infection with unit of admission and mechanically ventilated status included. Supplemental Table 9. Features driving separation in community structure identified by random forest achieving significance after correcting for feature importance bias. Supplemental Figure 1. No relationship between unit of admission and bacterial density. We found no significant difference in bacterial density for patients admitted to different hospital units ( $p=0.33$ by Kruskal-Wallis test).

Additional file 2.

\section{Acknowledgements}

This research was supported in part by the Michigan Microbiome Project and by work performed by The University of Michigan Microbiome Core. The authors thank Jennifer Baker, Piyush Ranjan, and John Erb-Downward for assistance with bioinformatic and statistical analyses.

\section{Authors' contributions}

RC, RJW, and RPD designed the experiments. RJW provided the rectal swab specimens. RC collected and analyzed clinical data. KH and NF performed DNA extraction, 16S rRNA gene amplicon sequencing, and ddPCR quantification of rectal swab specimens. RC and CAB performed $16 \mathrm{~S}$ rRNA analysis of rectal swab specimens. RPD provided critical analysis and discussion. RC wrote the first draft, and all authors participated in revision of the manuscript. The author(s) read and approved the final manuscript.

\section{Funding}

This work was supported by the National Institutes of Health [grant numbers R01 HL144599 to RPD, R01 Al143852 to RJW, 5T32 HL007749-27 to RC].

\section{Availability of data and materials}

The dataset supporting the results of this article has been posted to the NIH Sequence Read Archive (accession number PRJNA633879). OTU tables, taxonomy classification tables, and metadata tables are available at https:// github.com/rishichanderraj/RectalSwab_BacterialDensity. Protected health information is not included in our repository, but investigators who wish to build on our data may send reasonable requests that guarantee patient safety and privacy to gain access to this data.

\section{Declarations}

Consent to publication

All authors read and approved this version of the manuscript for publication.

\section{Ethics approval and consent to participate}

This study was approved by the University of Michigan Institutional Research Board (HUM00102282).

\section{Competing interests}

The authors declare no competing interests.

\section{Author details}

${ }^{1}$ Division of Infectious Diseases, Department of Internal Medicine, University of Michigan Medical School, Ann Arbor, MI, USA. ${ }^{2}$ Division of Pulmonary and Critical Care Medicine, Department of Internal Medicine, University of Michigan Medical School, Ann Arbor, MI, USA. ${ }^{3}$ Institute for Research on Innovation and Science, Institute for Social Research, University of Michigan, Ann Arbor, MI, USA. ${ }^{4}$ Computational Medicine and Bioinformatics, University of Michigan Medical School, Ann Arbor, MI, USA. ${ }^{5}$ Department of Microbiology and Immunology, University of Michigan Medical School, Ann Arbor, MI, USA. ${ }^{6}$ Weil Institute for Critical Care Research \& Innovation, MI, Ann Arbor, USA. ${ }^{7}$ Pulmonary and Critical Care Medicine, University of Michigan Health System, 6220 MSRB III / SPC 5642, 1150 W. Medical Center Dr, Ann Arbor, Ml 48109-5642, USA. 
Received: 30 March 2021 Accepted: 18 October 2021

Published online: 06 January 2022

\section{References}

1. Cani PD. Human gut microbiome: hopes, threats and promises. Gut. 2018;67:1716-25. https://doi.org/10.1136/gutjnl-2018-316723.

2. Schloss PD. The effects of alignment quality, distance calculation method, sequence filtering, and region on the analysis of 16S rRNA gene-based studies. PLoS Comput Biol. 2010;6:e1000844. https://doi.org/10.1371/ journal.pcbi.1000844.

3. Barriuso J, Valverde JR, Mellado RP. Estimation of bacterial diversity using next generation sequencing of 16S rDNA: a comparison of different workflows. BMC Bioinformatics. 2011;12:1-11. https://doi.org/10.1186/ 1471-2105-12-473.

4. Krebs JC. Ecological methodology BT - Ecological methodology. In: Ecological methodology. 2nd ed. Menlo Park: Benjamin/Cummings; 1999. p. 620. http://hdl.handle.net/2027/uc1.31822026230284. Accessed 21 Oct 2020

5. Contijoch EJ, Britton GJ, Yang C, Mogno I, Li Z, Ng R, et al. Gut microbiota density influences host physiology and is shaped by host and microbial factors. Elife. 2019;8:1-26.

6. Vandeputte D, Kathagen G, D'Hoe K, Vieira-Silva S, Valles-Colomer M, Sabino J, et al. Quantitative microbiome profiling links gut community variation to microbial load. Nature. 2017;551:507-11. https://doi.org/10. 1038/nature24460.

7. Vandeputte D, Falony G, Vieira-silva S, Tito RY, Joossens M, Raes J. Stool consistency is strongly associated with gut microbiota richness and composition, enterotypes and bacterial growth rates; 2015. p. 1-6.

8. Vieira-Silva S, Sabino J, Valles-Colomer M, Falony G, Kathagen G, Caenepeel C, et al. Quantitative microbiome profiling disentangles inflammation- and bile duct obstruction-associated microbiota alterations across PSC/IBD diagnoses. Nat Microbiol. 2019;4:1826-31. https://doi.org/10. 1038/s41564-019-0483-9.

9. Bassis CM, Moore NM, Lolans K, Seekatz AM, Weinstein RA, Young VB, et al. Comparison of stool versus rectal swab samples and storage conditions on bacterial community profiles. BMC Microbiol. 2017;17:78. https://doi. org/10.1186/s12866-017-0983-9.

10. Budding $A E$, Grasman ME, Eck A, Bogaards JA, Vandenbroucke-Grauls CMJE, van Bodegraven AA, et al. Rectal Swabs for Analysis of the Intestinal Microbiota. PLoS One. 2014;9:e101344. https://doi.org/10.1371/journal. pone.0101344.

11. Biehl LM, Garzetti D, Farowski F, Ring D, Koeppel MB, Rohde H, et al. Usability of rectal swabs for microbiome sampling in a cohort study of hematological and oncological patients. PLoS One. 2019;14:e0215428.

12. Salter SJ, Cox MJ, Turek EM, Calus ST, Cookson WO, Moffatt MF, et al. Reagent and laboratory contamination can critically impact sequence-based microbiome analyses. BMC Biol. 2014;12:1-12. https://doi.org/10.1186/ s12915-014-0087-z.

13. de Goffau MC, Lager S, Salter SJ, Wagner J, Kronbichler A, Charnock-Jones DS, et al. Recognizing the reagent microbiome. Nature. Microbiology. 2018;3:851-3. https://doi.org/10.1038/s41564-018-0202-y.

14. Eisenhofer R, Weyrich LS, Minich JJ, Marotz C, Cooper A, Knight R. Contamination in low microbial biomass microbiome studies : issues and recommendations. Trends Microbiol. 2018:27:105-17. https://doi.org/10. 1016/j.tim.2018.11.003.

15. Chanderraj R, Brown CA, Hinkle K, Falkowski N, Ranjan P, Dickson RP, et al. Gut microbiota predict Enterococcus expansion but not vancomycinresistant Enterococcus acquisition. mSphere. 2020;5. https://doi.org/10. 1128/mSphere.00537-20.

16. Muto CA, Jernigan JA, Ostrowsky BE, Richet HM, Jarvis WR, Boyce JM, et al SHEA guideline for preventing nosocomial transmission of multidrugresistant strains of Staphylococcus aureus and enterococcus. Infect Control Hosp Epidemiol. 2003;24:362-86.

17. Kozich JJ, Westcott SL, Baxter NT, Highlander SK, Schloss PD. Development of a dual-index sequencing strategy and curation pipeline for analyzing amplicon sequence data on the miseq illumina sequencing platform. Appl Environ Microbiol. 2013;79:5112-20.
18. Hindson BJ, Ness KD, Masquelier DA, Belgrader P, Heredia NJ, Makarewicz AJ, et al. High-throughput droplet digital PCR system for absolute quantitation of DNA copy number. Anal Chem. 2011;83:8604-10.

19. Pinheiro LB, Coleman VA, Hindson CM, Herrmann J, Hindson BJ, Bhat S, et al. Evaluation of a droplet digital polymerase chain reaction format for DNA copy number quantification. Anal Chem. 2012;84:1003-11. https:// doi.org/10.1021/ac202578x.

20. Sze MA, Abbasi M, Hogg JC, Sin DD. A comparison between droplet digital and quantitative PCR in the analysis of bacterial $16 \mathrm{~S}$ load in lung tissue samples from control and COPD GOLD 2. PLoS One. 2014;9:e110351. https://doi.org/10.1371/journal.pone.0110351.

21. GitHub - SchlossLab/MiSeq_WetLab_SOP. https://github.com/Schlo ssLab/MiSeq_WetLab_SOP/. Accessed 27 Apr 2020.

22. Vincent J-L, Moreno R, Takala J, Willatts S, De Mendonça A, Bruining H, et al. The SOFA (sepsis-related organ failure assessment) score to describe organ dysfunction/failure. Intensive Care Med. 1996;22:707-10. https:// doi.org/10.1007/BF01709751.

23. Vincent J-L, de Mendonca A, Cantraine F, Moreno R, Takala J, Suter PM, et al. Use of the SOFA score to assess the incidence of organ dysfunction/failure in intensive care units: results of a multicenter, prospective study. Crit Care Med. 1998;26:1793-800 https://journals.Iww.com/ccmjournal/Fulltext/1998/ 11000/Use_of_the_SOFA_score_to_assess_the_incidence_of.16.aspx.

24. Ferreira FL, Bota DP, Bross A, Mélot C, Vincent J-L. Serial evaluation of the SOFA score to predict outcome in critically ill patients. JAMA. 2001;286:1754-8. https://doi.org/10.1001/jama.286.14.1754.

25. Cárdenas-Turanzas M, Ensor J, Wakefield C, Zhang K, Wallace SK, Price KJ, et al. Cross-validation of a sequential organ failure assessment scorebased model to predict mortality in patients with cancer admitted to the intensive care unit. J Crit Care. 2012;27:673-80. https://doi.org/10.1016/j. jcrc.2012.04.018.

26. Charlson ME, Pompei P, Ales KL, Mackenzie CR. A new method of classifying prognostic comorbidity in longitudinal studies: development and validation. J Chronic Dis. 1987:40:373-83. https://doi.org/10.1016/00219681(87)90171-8.

27. Quan H, Li B, Couris CM, Fushimi K, Graham P, Hider P, et al. Updating and validating the charlson comorbidity index and score for risk adjustment in hospital discharge abstracts using data from 6 countries. Am J Epidemiol. 2011;173:676-82.

28. Radovanovic D, Seifert B, Urban P, Eberli FR, Rickli H, Bertel O, et al. Validity of Charlson comorbidity index in patients hospitalised with acute coronary syndrome. Insights from the nationwide AMIS Plus registry 2002-2012. Heart. 2014:100:288-94.

29. Runyon BA. Introduction to the revised American Association for the study of liver diseases practice guideline management of adult patients with ascites due to cirrhosis 2012. Hepatology. 2013;57:1651-3. https:// doi.org/10.1002/hep.26359.

30. Hooton TM, Bradley SF, Cardenas DD, Colgan R, Geerlings SE, Rice JC, et al. Diagnosis, prevention, and treatment of catheter-aassociated urinary tract infection in adults: 2009 international clinical practice guidelines from the infectious diseases society of America. Clin Infect Dis. 2010:50:625-63. https://doi.org/10.1086/650482.

31. Gupta K, Hooton TM, Naber KG, Wullt B, Colgan R, Miller LG, et al. International clinical practice guidelines for the treatment of acute uncomplicated cystitis and pyelonephritis in women: A 2010 update by the Infectious Diseases Society of America and the European Society for Microbiology and Infectious Diseases. Clin Infect Dis. 2011;52:103-20. https://doi.org/10.1093/cid/ciq257.

32. Klompas M, Kleinman K, Khan Y, Evans RS, Lloyd JF, Stevenson K, et al. Rapid and reproducible surveillance for ventilator-associated pneumonia. Clin Infect Dis. 2012;54:370-7. https://doi.org/10.1093/cid/cir832.

33. Horan TC, Andrus M, Dudeck MA. CDC/NHSN surveillance definition of health care-associated infection and criteria for specific types of infections in the acute care setting. Am J Infect Control. 2008;36:309-32. https://doi.org/10.1016/j.ajic.2008.03.002.

34. CDC, Oid, Ncezid, DHQP. Pneumonia (Ventilator-associated [VAP] and non-ventilator-associated Pneumonia [PNEU]) Event. 2020.

35. Stevens DL, Bisno AL, Chambers HF, Dellinger EP, Goldstein EJC, Gorbach SL, et al. Practice guidelines for the diagnosis and management of skin and soft tissue infections: 2014 update by the infectious diseases society of America. Clin Infect Dis. 2014;59:e10-52. https://doi.org/10.1093/cid/ciu296. 
36. R Development Core Team R. R: a language and environment for statistical computing; 2019. https://doi.org/10.1007/978-3-540-74686-7.

37. Therneau T. A Package for Survival Analysis in S; 2015

38. Schloss PD, Westcott SL, Ryabin T, Hall JR, Hartmann M, Hollister EB, et al. Introducing mothur: open-source, platform-independent, communitysupported software for describing and comparing microbial communities. Appl Environ Microbiol. 2009;75:7537-41.

39. Schloss PD. MiSeq SOP:mothur. MiSeq SOP:mothur. 2019. http://www. mothur.org/wiki/MiSeq_SOP. Accessed 11 Feb 2019.

40. Quast C, Pruesse E, Yilmaz P, Gerken J, Schweer T, Yarza P, et al. The SILVA ribosomal RNA gene database project: improved data processing and webbased tools. Nucleic Acids Res. 2012;41:D590-6. https://doi.org/10.1093/nar/ gks1219.

41. Needleman SB, Wunsch CD. A general method applicable to the search for similarities in the amino acid sequence of two proteins. J Mol Biol. 1970:48:443-53.

42. Caporaso JG, Bittinger K, Bushman FD, DeSantis TZ, Andersen GL, Knight R. PyNAST: a flexible tool for aligning sequences to a template alignment. Bioinformatics. 2010;26:266-7. https://doi.org/10.1093/bioinformatics/btp636.

43. Wang Q, Garrity GM, Tiedje JM, Cole JR. Naïve Bayesian classifier for rapid assignment of rRNA sequences into the new bacterial taxonomy. Appl Environ Microbiol. 2007;73:5261-7.

44. Sogin ML, Morrison HG, Huber JA, Welch DM, Huse SM, Neal PR, et al. Microbial diversity in the deep sea and the underexplored "rare biosphere". Proc Natl Acad Sci U S A. 2006;103:12115-20.

45. Westcott SL, Schloss PD. OptiClust, an improved method for assigning amplicon-based sequence data to operational taxonomic units. mSphere. 2017;2:e00073-17. https://doi.org/10.1128/mSphereDirect.00073-17.

46. Matthews BW. Comparison of the predicted and observed secondary structure of T4 phage lysozyme. BBA Protein Struct. 1975;405:442-51.

47. Oksanen J, Blanchet FG, Kindt R, Legendre P, Minchin P, O'Hara RB, et al. Vegan: Community ecology package. R package version 2.0-2. 2012.

48. Wang Y, Naumann U, Wright ST, Warton DI. Mvabund- an R package for model-based analysis of multivariate abundance data. Methods Ecol Evol. 2012:3:471-4.

49. Wright MN, Ziegler A. ranger: A Fast Implementation of Random Forests for High Dimensional Data in $\mathrm{C}++$ and R. Journal of Statistical Software. 2017;77(1):1-17. https://doi.org/10.18637/jss.v077.i01.

50. Kuhn M. Building predictive models in R using the caret package. J Stat Softw. 2008;28:1-26.

51. Leisch F. FlexMix: a general framework for finite mixture models and latent class regression in R. J Stat Softw. 2004;11:1-18. https://doi.org/10.18637/jss. v011.i08.

52. Kembel SW, Wu M, Eisen JA, Green JL. Incorporating 165 gene copy number information improves estimates of microbial diversity and abundance. PLoS Comput Biol. 2012;8:16-8.

53. Louca S, Doebeli M, Parfrey LW. Correcting for 16S rRNA gene copy numbers in microbiome surveys remains an unsolved problem. Microbiome. 2018:6:1-12.

54. Dickson RP, Erb-Downward JR, Freeman CM, Walker N, Scales BS, Beck JM, et al. Changes in the lung microbiome following lung transplantation include the emergence of two distinct pseudomonas species with distinct clinical associations. PLoS One. 2014;9:e97214. https://doi.org/10.1371/journ al.pone.0097214.

55. Altmann A, Toloşi L, Sander O, Lengauer T. Permutation importance: a corrected feature importance measure. Bioinformatics. 2010;26:1340-7. https:// doi.org/10.1093/bioinformatics/bta134.

56. Sun Z, Harris HMB, McCann A, Guo C, Argimón S, Zhang W, et al. Expanding the biotechnology potential of lactobacilli through comparative genomics of 213 strains and associated genera. Nat Commun. 2015;6:8322.

57. Collins FWJ, O'Connor PM, O'Sullivan O, Gómez-Sala B, Rea MC, Hill C, et al. Bacteriocin gene-trait matching across the complete Lactobacillus Pangenome. Sci Rep. 2017;7:1-14.

58. Pettigrew MM, Gent JF, Kong Y, Hal pin AL, Pineles L, Harris AD, et al. Gastrointestinal microbiota disruption and risk of colonization with carbapenemresistant Pseudomonas aeruginosa in ICU patients. Clin Infect Dis. 2018. https://doi.org/10.1093/cid/ciy936.

59. Shono Y, Docampo MD, Peled JU, Perobelli SM, Velardi E, Tsai JJ, et al. Increased GVHD-related mortality with broad-spectrum antibiotic use after allogeneic hematopoietic stem cell transplantation in human patients and mice. Sci Transl Med. 2016:8:339ra71.
60. Tamburini FB, Andermann TM, Tkachenko E, Senchyna F, Banaei N, Bhatt AS. Precision identification of diverse bloodstream pathogens in the gut microbiome. Nat Med. 2018;24:1809-14. https://doi.org/10.1038/ s41591-018-0202-8.

61. Zhai B, Ola M, Tosini NL, Joshowitz S, Littmann E, Morjaria SM, et al. Candida intestinal domination precedes fungal infections bloodstream in allogeneic hematopoietic cell transplant patients. Biol Blood Marrow Transplant. 2019;25:S340-1. https://doi.org/10.1016/J.BBMT.2018.12.552.

62. Taur Y, Xavier JB, Lipuma L, Ubeda C, Goldberg J, Gobourne A, et al. Intestinal domination and the risk of bacteremia in patients undergoing allogeneic hematopoietic stem cell transplantation. Clin Infect Dis. 2012;55:905-14. https://doi.org/10.1093/cid/cis580.

63. Haak BW, Littmann ER, Chaubard JL, Pickard AJ, Fontana E, Adhi F, et al. Impact of gut colonization with butyrate-producing microbiota on respiratory viral infection following allo-HCT. Blood. 2018;131:2978-86.

64. Freedberg DE, Zhou MJ, Cohen ME, Annavajhala MK, Khan S, Moscoso DI, et al. Pathogen colonization of the gastrointestinal microbiome at intensive care unit admission and risk for subsequent death or infection. Intensive Care Med. 2018;44:1203-11. https://doi.org/10.1007/s00134-018-5268-8.

65. Viviani M, Van Saene HKF, Pisa F, Lucangelo U, Silvestri L, Momesso E, et al. The role of admission surveillance cultures in patients requiring prolonged mechanical ventilation in the intensive care unit. Anaesth Intensive Care. 2010;38:325-35.

66. Uffelen R, Saene HK, Fidler V, Löwenberg A, van Uffelen R, van Saene HKF, et al. Oropharyngeal flora as a source of bacteria colonizing the lower airways in patients on artificial ventilation. Intensive Care Med. 1984;10:233-7. https://doi.org/10.1007/BF00256259.

67. Li N, Ma J, Guarnera MA, Fang H, Cai L, Jiang F. Digital PCR quantification of miRNAs in sputum for diagnosis of lung cancer. J Cancer Res Clin Oncol. 2014;140:145-50. https://doi.org/10.1007/s00432-013-1555-5.

68. Strain MC, Richman DD. New assays for monitoring residual HIV burden in effectively treated individuals. Curr Opin HIV AIDS. 2013;8:106-10. https:// doi.org/10.1097/COH.0b013e32835d811b.

69. Dickson RP, Erb-Downward JR, Prescott HC, Martinez FJ, Curtis JL, Lama VN, et al. Cell-associated bacteria in the human lung microbiome. Microbiome. 2014;2:28. https://doi.org/10.1186/2049-2618-2-28.

70. Erb-Downward JR, Thompson DL, Han MK, Freeman CM, McCloskey L, Schmidt LA, et al. Analysis of the lung microbiome in the "healthy" smoker and in COPD. PLoS One. 2011;6:e16384. https://doi.org/10.1371/journal. pone.0016384.

71. Madsen JL, Graff J. Effects of ageing on gastrointestinal motor function. Age Ageing. 2004;33:154-9. https://doi.org/10.1093/ageing/afh040.

72. Varga F. Transit time changes with age in the gastrointestinal tract of the rat. Digestion. 1976;14:319-24. https://doi.org/10.1159/000197947.

73. Choung RS, Rey E, Locke GR, Schleck CD, Baum C, Zinsmeister AR, et al. Chronic constipation and co-morbidities: a prospective population-based nested case-control study. United European Gastroenterol J. 2016;4:142-51. https://doi.org/10.1177/2050640614558476.

74. Bansal S, Nguyen JP, Leligdowicz A, Zhang Y, Kain KC, Ricciuto DR, et al. Rectal and naris swabs: practical and informative samples for analyzing the microbiota of critically ill patients. mSphere. 2018;3. https://doi.org/10.1128/ msphere.00219-18.

75. McDonald D, Ackermann G, Khailova L, Baird C, Heyland D, Kozar R, et al. Extreme dysbiosis of the microbiome in critical illness. mSphere. 2016;1:e00199-16. https://doi.org/10.1128/mSphere.00199-16.

76. Livanos AE, Snider EJ, Whittier S, Chong DH, Wang TC, Abrams JA, et al. Rapid gastrointestinal loss of Clostridial clusters IV and XIVa in the ICU associates with an expansion of gut pathogens. PLoS One. 2018;13:e0200322. https:// doi.org/10.1371/journal.pone.0200322.

77. Rao K, Patel AR, Seekatz AM, Bassis CM, Sun Y, Henig O, et al. Gut microbiome features are associated with sepsis onset and outcomes 12 Running Title: microbiome disruption at sepsis onset. bioRxiv. 2021;:2021.01.08.426011. https://doi.org/10.1101/2021.01.08.426011.

\section{Publisher's Note}

Springer Nature remains neutral with regard to jurisdictional claims in published maps and institutional affiliations. 